\title{
TECHNICAL TIP
}

\section{The barrel and cuff technique for a blood- less field}

T MITCHELL, S HIGNETT, R CHANDRASEKAR

Department of Vascular Surgery, Arrowe Park Hospital, Upton, Merseyside, UK

\section{CORRESPONDENCE TO}

R Chandrasekar, Department of Vascular Surgery, Arrowe Park Hospital, Upton, Merseyside CH49 5PE, UK

E: ramasubramanyan.chandrasekar@whnt.nhs.uk

Revision surgery in patients with well-developed arteriovenous fistula is difficult, particularly when dissecting around sections which are adherent to the skin as a result of repeated needling during haemodialysis. Using a tourniquet to compress the calcified brachial artery in obese arms is usually unsuccessful. Our technique involves placing an appropriate length of the barrel of a 20$\mathrm{ml}$ syringe over the brachial artery and under the tourniquet. After exsanguination of the arm, inflation of the tourniquet results in total arterial occlusion, as the barrel occludes the brachial artery against the humerus. There has been no incidence of neuropraxia with this technique but some patients with complications may be unsuitable.

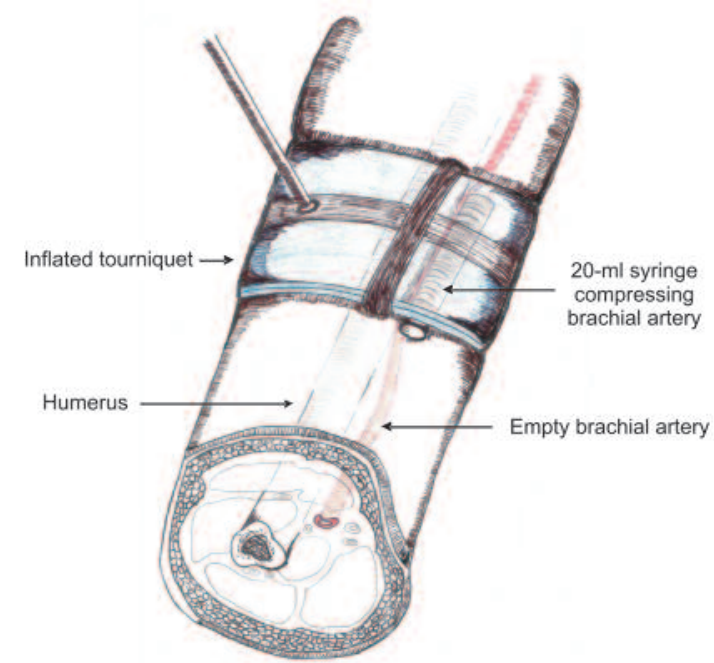

Figure 1 Diagram illustrating a cross-section through the arm of the barrel and cuff technique.

\section{e-Letters - new additions}

Since the last list appeared in the Annals, the following letters have been published on our website <http://www.rcseng.ac.uk/publications/eletters/>:

Stenting for large bowel obstruction - evolution of a service in a district general hospital - 2 responses

Anterior shoulder dislocation - 2 responses

Complication of oesophagoscopy and anticoagulation -1 response

Henoch-Schonlein purpura with ischaemic bowel - 1 response

The acute blue finger: management and outcome -1 response

The cost of ignoring acute cholecystectomy - 1 response

The timing of calcium measurements in helping to predict temporary and permanent hypocalcaemia in patients having completion and total thyroidectomies -2 responses

A randomised trial of conventional versus BAUS procedure-specific consent forms for transurethral resection of prostate -1 response

Acetate templating for total hip arthroplasty using PACS - 1 response

A study of microbial colonisation of orthopaedic tourniquets -2 responses 